\title{
Autoenclausuramento, degradação e poética do espaço em Crônica da casa assassinada, de Lúcio Cardoso
}

Messias Lisboa Gonçalves ${ }^{1}$

Sílvio Augusto de Oliveira Holanda²

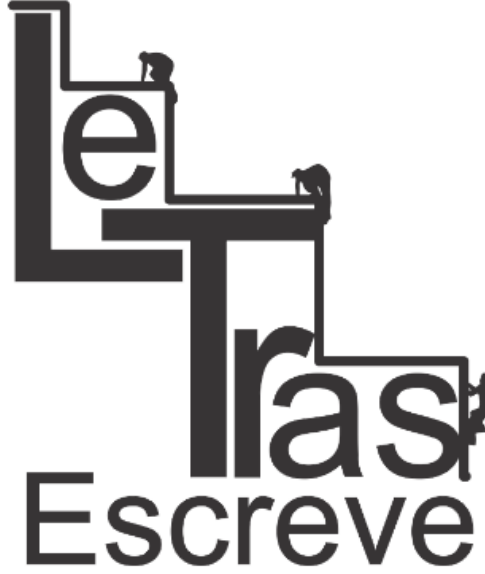

(ISSN 2238-8060)
Resumo: A carreira literária do mineiro Lúcio Cardoso (1912-1968) iniciou em 1934, com a publicação de Maleita. No entanto, Lúcio Cardoso se consagrou, definitivamente, como romancista com Crônica da casa assassinada, publicado em 1959. A trama ficcional gira em torno dos Meneses, uma família que praticamente rege a cidade, sendo considerada uma espécie de "realeza" local. Porém, apesar do aparente ar de superioridade e riqueza, eles estão em processo de falência. Sendo assim, o romance trata, de forma não linear, da decadência e fragmentação de uma família mineira burguesa e tradicional. Deste modo, considerando que a casa dos Meneses desempenha um papel fundamental na constituição e desenrolar da trama, o objetivo fulcral deste trabalho é demonstrar a estreita relação entre Timóteo e o seu autoenclausuramento em um dos cômodos da casa. Devido à enorme complexidade de cada figura ficcional, nossa análise limita-se à reflexão deste personagem que se destaca ao desafiar suas paixões e expor suas mazelas. Para tanto, buscamos, principalmente, em Gaston Bachelard (1978) e Antonio Dimas (1994) um suporte teórico para nosso estudo.

Palavras-chave: Autoenclausuramento. Espaço. Quarto. Timóteo.

Abstract: The literary career of Brazilian writer Lúcio Cardoso (1912-1968) began in 1934, with the publication of Maleita. However, Lúcio Cardoso was consecrated definitely as a novelist with Crônica da casa assassinada, published in 1959. The plot fiction happen around the Meneses's, a family that pretty much rules the city, and considered a kind of "royalty" in this town. However, despite the apparent air of superiority and wealth, they are in bankruptcy. Thus, the novel comes nonlinearly, decay and disintegration of this bourgeois and traditional family. Thus, considering that the house of Meneses plays a key role in setting up and running of the plot, the central objective of this paper is to demonstrate the close relationship between Timóteo and his self-confinement in one of the rooms in the house. Due to the enormous complexity of each fictional figure, our analysis is limited to the reflection of this character that stands out to challenge their passions and express their ills. Therefore, we research mainly in Gaston Bachelard (1978) and Antonio Dimas (1994) a theoretical support for our study. Keywords: Self-confinement. Space. Bedroom. Timóteo.

\footnotetext{
${ }^{1}$ Mestrando em Estudos Literários pelo Programa de Pós-Graduação em Letras - Estudos Literários pela Universidade Federal do Pará. E-mail: meslisboa@gmail.com.

2 Doutor em Letras pela USP. Professor associado IV da Universidade Federal do Pará. E-mail: eellip@hotmail.com.
}

https://periodicos.unifap.br/index.php/letras

Macapá, v. 6, n. I, Io semestre, 2016. 


\section{Para início de conversa...}

A carreira literária do mineiro Lúcio Cardoso (1912-1968) iniciou em 1934, com a publicação de Maleita, que alcançou sucesso e agradou a escritores e críticos a ele contemporâneos. Desde então, praticamente a cada ano presenteava o público leitor com uma nova obra. No entanto, Lúcio Cardoso se consagrou, definitivamente, como romancista com Crônica da casa assassinada, publicado em 1959.

O romance se passa no interior de Minas Gerais, no desenrolar do século $X X$. A trama ficcional gira em torno dos Meneses, uma família que praticamente rege a cidade, sendo considerada uma espécie de "realeza" local. Apesar do aparente ar de superioridade e riqueza, eles estão em decadência, porque as suas propriedades já não possuem tanto valor.

Sendo assim, o romance apresenta, de forma não linear, a decadência e fragmentação de uma família mineira burguesa e tradicional. A história é narrada por várias vozes, incluindo membros da família Meneses e habitantes de Vila Velha, uma cidade ficcional do interior de Minas Gerais.

O enredo é construído por meio de diários, cartas, (ISSN 2238-8060) narrativas, confissões, depoimentos e memórias dos personagens que compõem o romance, como Nina, Valdo e Timóteo Menezes, caracterizados como personagens principais. Ana Laura Corrêa (2008) destaca que:

A justaposição de formas variadas de narrar constrói um conjunto não-linear, um todo, que é o romance, mas que Lúcio Cardoso decidiu compor de forma fragmentada. A maneira como o romance foi composto aponta para um movimento duplo: de integração e desintegração, de encontro e desencontro, na mesma medida da justaposição das formas de narrar que se procuram e se desgarram (CORRÊA, 2008, p. 91). 
Concordamos com a reflexão de Ana Laura Corrêa (2008) de que o romance é composto de narrativas fragmentadas, que em certos momentos se completam e em outros se contradizem. Os fatos vão sendo apresentados a partir das visões que os personagens têm destes, contribuindo com a instauração de vários narradores-personagens que, em uma escala de maior interpretação, revelam as suas visões acerca do mundo. Luiz Andrade (2010) assegura que:

Os fragmentos são reunidos num jogo de sobreposições temporais, daí forma-se a trama para os leitores e para as próprias personagens [...]. Nós conhecemos partes da história que, na maioria das vezes, são apresentadas de forma contraditória pelos narradores. As próprias personagens, pelos relatos, vão descobrindo, construindo, desmanchando ou confirmando, amarrando os fatos ou confundindo-os a partir do que é narrado pelos outros (ANDRADE, 2010, p. 1276).

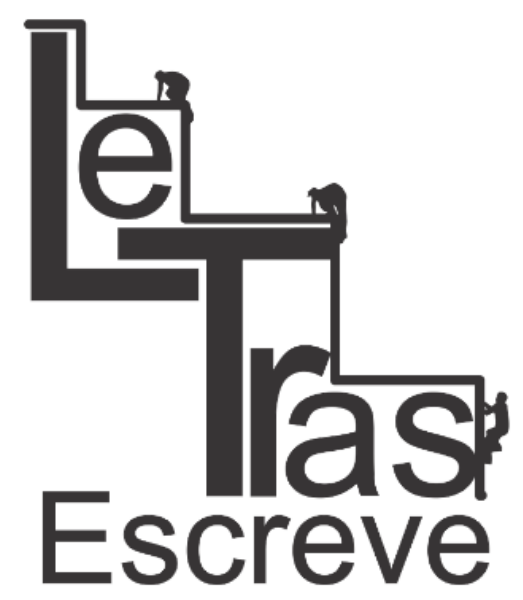

(ISSN 2238-8060)

Apesar da narrativa fragmentada, a casa apresenta uma representatividade sólida na visão dos personagens, que de alguma maneira, sofrem a influência que a casa patriarcal dos Meneses exerce sobre os seus habitantes. Neste sentido, a casa aparece na obra como um dos principais personagens ou, no mínimo, como um instrumento que age na vida daquela família que outrora tivera grande poder, influenciando nos sentimentos e atitudes das pessoas que nela habitam.

Deste modo, considerando que a casa dos Meneses desempenha um papel fundamental na constituição e desenrolar da trama, pesquisamos o espaço como elemento primordial na constituição do romance. O objetivo fulcral deste trabalho é demonstrar a estreita relação entre Timóteo e 0 seu autoenclausuramento em um dos cômodos da casa.

Finalmente, elaboramos uma análise sobre a configuração simbólica do espaço na casa dos Meneses e de como isso interferiu na trajetória de Timóteo. Devido à enorme complexidade de cada figura ficcional que habita a casa, nossa análise limita-se à reflexão 
sobre ele, que entre os demais membros da família Meneses é o que apresenta uma visão mais centrada e racional dos outros personagens. Além de Timóteo destacar-se ao desafiar suas paixões e expor suas mazelas.

\section{A simbologia do espaço}

De acordo com Dimas (1994), "entre as várias armadilhas virtuais de um texto, o espaço pode alcançar estatuto tão importante quanto outros componentes da narrativa, tais como foco narrativo, personagem, tempo, estrutura" (DIMAS, 1994, p. 1, grifo nosso). Dimas ressalta que "armadilhas virtuais" de um texto literário, como por exemplo, o modo de narrar e organização do tempo, são que o tornam mais rico e, desta forma, a leitura fica mais prazerosa e instigante. Assim, o espaço em um romance pode ter grande relevância e importância e, além disso, determinar os caminhos a serem tomados na obra.

A forma com que o autor deixa os traços do espaço numa obra pode ser fundamental, determinando, assim, o quanto o espaço será importante para a análise do romance. Segundo Dimas (1994), quando o autor mostra os elementos que constituem o romance "de forma abusiva e repetitiva, deixando-as expostas demais, o que poderá provocar a adesão do leitor fácil ou a repulsa do leitor inteligente" (DIMAS, 1994, p. 1). Fica evidente que existem textos literários em que o espaço atua como protagonista do enredo, uma vez que o espaço interfere na trama ficcional direcionando os rumos que a mesma tomará, isto é, ele não é construído no texto de forma simples e aleatória, pelo contrário, apresenta um simbolismo no seu conteúdo, tornando-se, assim, um complexo e interessante objeto de estudo.

O espaço ganha importância em um romance a partir do instante em que o autor usa deste elemento para atuar nele. $E$ isso não ocorre simplesmente de forma decorativa e passiva. Conforme 
os esclarecimentos de Dimas (1994), podemos observar que "inabalável na convicção de que o ambiente modela e determina a conduta humana" (DIMAS, 1994, p. 11). De acordo com Hall (1994):

Existem literalmente milhares de experiências que inconscientemente nos provam que o espaço é um meio de comunicação. No entanto, é provável que não tivéssemos consciência desse fato se não percebêssemos que o espaço é organizado de forma diferente em cada cultura (HALL, 1994, p. 188).

O "se comunicar" do espaço acontece na narrativa ficcional e é preciso entender toda a dimensão e significado que o elemento do espaço assume no romance. Hall (1994) assevera que "muito do que acontece na utilização e organização do espaço fornece-nos indicações importantes sobre os hábitos específicos" (HALL, 1994,

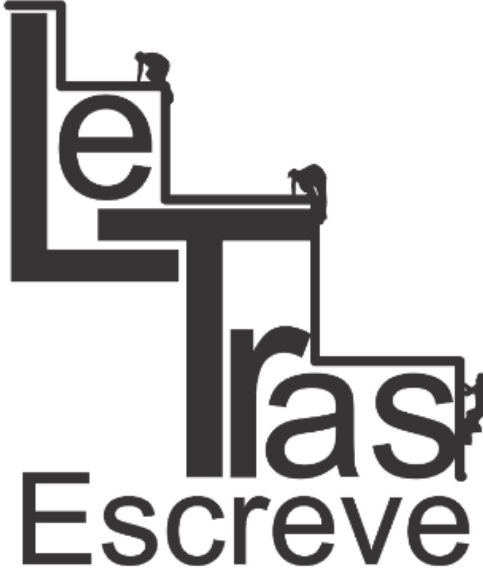

(ISSN 2238-8060) p. 197). Logo, o estudo do espaço é capaz de revelar os costumes e denunciar as particularidades dos indivíduos que nele se arrolam.

Depois do que já foi aludido até aqui, é possível afirmar que o espaço tem um relacionamento de diálogo com as pessoas, pois é lógico que as pessoas constroem o ambiente, o espaço em que habitam. No entanto, elas também são moldadas pelo espaço que está a sua volta. É preciso considerar a maneira que o espaço é ocupado, como nos diz Bachelard (1978). Segundo o autor, "é preciso dizer então como habitamos nosso espaço vital de acordo com todas as dialéticas da vida, como nos enraizamos, dia a dia, num canto do mundo" (BACHELARD, 1978, p. 200).

Este canto do mundo a que Bachelard (1978) se refere é a casa e não há como estudarmos o espaço do romance, sem levarmos em consideração o importante papel que a casa desempenha. Sobre a casa, Bachelard (1978) afirma que "a casa é o nosso canto do mundo. Ela é, como se diz frequentemente, nosso primeiro universo. É um verdadeiro cosmos. Um cosmos em toda a acepção do termo" (BACHELARD, 1978, p. 200). É fundamental 


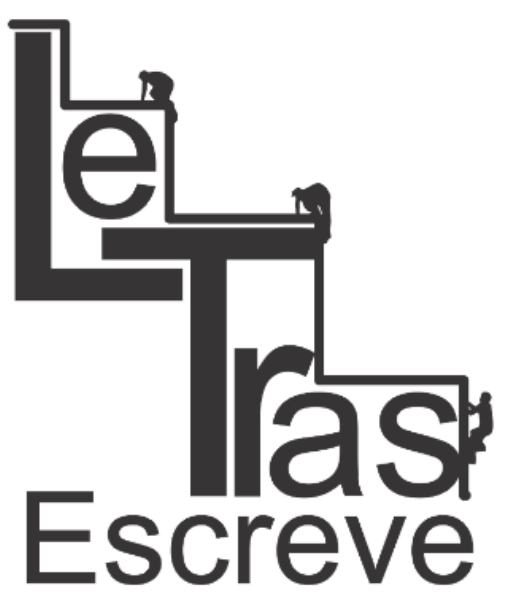

(ISSN 2238-8060)

entendermos o papel que a casa desempenha na vida das pessoas e tudo aquilo que ela representa.

A casa é o espaço onde o ser humano encontra segurança, sente-se livre das pressões do mundo exterior e sonha. Conforme Bachelard (1978) "se nos perguntassem qual o benefício mais precioso da casa, diríamos: a casa abriga o devaneio, a casa protege o sonhador, a casa nos permite sonhar em paz" (BACHELARD, 1978, p. 201). Observamos também que cada casa tem suas características peculiares que influenciam no comportamento dos seus moradores.

Seguindo esta afirmação, Bachelard (1978) reflete "bem entendido, é graças à casa que um grande número de nossas lembranças estão guardadas e se a casa se complica um pouco, se tem porão e sótão, cantos e corredores, nossas lembranças têm refúgios cada vez mais bem caracterizados" (BACHELARD, 1978, p. 202). Percebemos que o espaço atua de forma que nos faz sonhar, guarda nossas lembranças e o tempo já não opera com a mesma intensidade sobre ele. Bachelard (1978) define que "em seus mil alvéolos, o espaço retém o tempo comprimido, o espaço serve para isso" (BACHELARD, 1978, p. 202).

Neste contexto, Bachelard (1978) revela que as casas possuem os seus cantos, ou seja, quartos, que proporcionam o velamento da intimidade:

[...] todo canto [quarto] de uma casa, todo ângulo de um aposento, todo espaço reduzido onde gostamos de nos esconder, de confabular conosco mesmos, é, para a imaginação, uma solidão, ou seja, o germe de um aposento, o germe de uma casa. § Sob muitos aspectos, o canto "vivido" recusa a vida, restringe a vida, esconde a vida. O canto é, então, uma negação do Universo. No canto, não se fala a si mesmo. Se nos recordamos das horas do canto, recordamos o silêncio, um silêncio de pensamentos (BACHELARD, 1978, p. 286).

Deste modo, o quarto simbolicamente é a personificação do velamento, de um lugar capaz de viabilizar o silêncio do mundo, uma

https://periodicos.unifap.br/index.php/letras

Macapá, v. 6, n. I, Io semestre, 2016. 
quebra com o mundo exterior e o exercício do pensamento solitário ao indivíduo, que possivelmente busca um habitat de maior identificação e de certo conforto espiritual perante o sua intimidade guardada. Para Bachelard (1978) "inicialmente, o canto é um refúgio que nos assegura um primeiro valor de ser: a imobilidade. Ele é a certeza local, o local próximo da minha imobilidade. O canto é uma espécie de meia-caixa, metade paredes, metade portas" (BACHELARD, 1978, p. 287). Assim, fica evidente que a ideia primeira do canto da casa é a de refúgio, certeza e imobilidade.

O refúgio no quarto da casa funciona como uma espécie de negação temporária da vida externa ao quarto e ao apagamento, também temporário, da memória do passado. De acordo com Bachelard (1978):

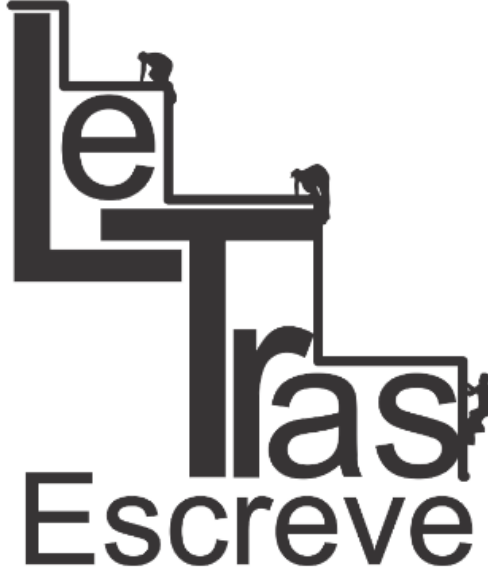

(ISSN 2238-8060)
O sonhador, no seu canto, pautou o mundo num devaneio minucioso que destrói um a um todos os objetos do mundo. $O$ canto transforma-se num armário de recordações. Tendo transposto os mil pequenos umbrais da desordem das coisas na poeira, os objetos-lembranças colocam o passado em ordem (BACHELARD, 1978, p. 290).

É importante ressaltar que o apagamento temporário do passado é solidário com a organização futura da memória, que se estabelece no espaço de privacidade e reflexão. A importância simbólica que o espaço traz para o romance é indiscutível. Quando o autor consegue usar este elemento com destreza e habilidade, ele não nos deixa dúvidas que a obra será um importante objeto de estudo, uma vez que o espaço nos dá pistas sobre o comportamento do personagem e revela sua intimidade profunda e mostra-nos seus sonhos, desejos, medos e fraquezas. Desta forma, percebemos que este elemento constitutivo do romance é uma complexa fonte reveladora da subjetividade de um personagem.

Levando em conta os aspectos aqui brevemente delineados sobre a simbolização do espaço na narrativa, seguimos para o estudo do personagem Timóteo, percebendo o quarto habitado por

https://periodicos.unifap.br/index.php/letras

Macapá, v. 6, n. I, Io semestre, 2016. 
ele como algo que transcende a mera ambientação ou decoração do enredo.

\section{As relações entre personagem e espaço habitado: Timóteo Meneses}

É importante salientar a disposição dos quartos na casa dos Meneses e a ocupação deles pelos irmãos: Valdo, Demétrio e Timóteo. De acordo com Luiz Andrade (2010), que realizou um interessante estudo sobre a simbologia do espaço em Crônica da casa assassinada, explica que:

Demétrio a certa altura da narrativa enclausura-se no seu quarto, que é o mais próximo da frente da casa; o de Valdo é marcado pela doença de Nina, de onde exalava um cheiro de podridão, situado no meio do corredor; por fim, Timóteo vive numa prisão [...] há anos vive isolado no cômodo situado na parte mais baixa da casa, perto da cozinha, em frente à dispensa. Por esses ambientes vemos a tensão familiar marcada pontualmente pela oposição Demétrio-Timóteo (ANDRADE, 2010, p. 1279-1280, grifo nosso).

Sendo assim, Timóteo ocupa o quarto localizado na área mais baixa da casa, perto da cozinha, já próximo dos aposentos dos empregados da família. Situação que nos remete à posição de inferioridade e recusa a que Timóteo é acometido pelos irmãos, principalmente, por Demétrio. Por meio da leitura do capítulo "Primeira confissão de Ana", ficamos sabendo dos motivos que levaram Timóteo ao exílio em um dos quartos da casa:

Timóteo sempre foi um temperamento esquisito, de hábitos fantásticos, o que obrigou a família a silenciar sobre ele - como se silencia sobre uma doença reservada. No princípio, assim que cheguei [Ana] à Chácara - então ainda luzindo aos fogos do seu esplendor final - ainda o vi algumas vezes, quando chegava da cidade em companhia de amigos. Até meu quarto, situado no fim do corredor, chegava o eco dos risos e das conversas que o bando mantinha no jardim. (Devo dizer, a bem da verdade, que Timóteo quase sempre chegava bêbado em casa - um estroina autêntico que dilapidava o dinheiro deixado

https://periodicos.unifap.br/index.php/letras

Macapá, v. 6, n. I, Io semestre, 2016. 
pelo pai, zombando da usura dos irmãos e triturando-os com seu desprezo.) (CARDOSO, 2009, p. 104-105).

É desta forma que a família o vê: como um "doente", um "degenerado", sob o qual deveria recair o silêncio e o isolamento. Assim, Timóteo também se apresenta como uma figura "estranha" e "diferente". O comportamento baderneiro de Timóteo irritava extraordinariamente o seu irmão mais velho Demétrio, marido de Ana, preocupado com a moral e o renome da família. Depois de uma intensa discussão travada com Demétrio, Timóteo se isola em seu quarto com receio de ser internado pelo irmão em um manicômio ou de ser abolido da herança da família, conforme é possível verificar no seguinte trecho da confissão de Ana:

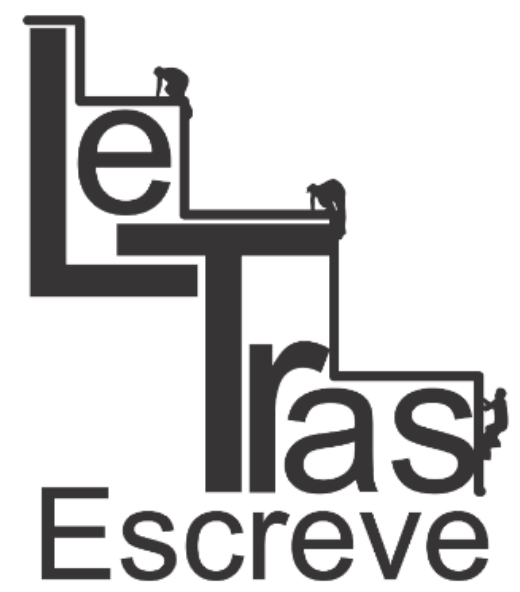

(ISSN 2238-8060)

A partir desse ponto, gritaram de tal modo que eu [Ana] pouco percebi do que se passava; assustada, deixei o quarto e pude enfim verificar que meu marido ameaçava Timóteo de prejudicá-lo em sua herança, internando-o num manicômio, caso ele persistisse em levar a mesma vida que levava naquele momento. [...] Houve uma pausa, a tensão se desfez. Mas creio que vem daí a esquisita decisão de Timóteo de jamais abandonar o quarto, temendo que o outro cumpra sua ameaça (CARDOSO, 2009, p. 105).

Por meio do esclarecimento concedido por Ana, torna-se evidente que Timóteo vai sendo moldado na obra por meio de seus comportamentos, como uma figura transgressora, que consequentemente recebe a reprovação de sua família arraigada em padrões sociais tradicionais, que temia um escândalo maior perante os demais habitantes da fictícia Vila Velha, na Zona da Mata mineira.

No decorrer da narrativa, é viável notar, embora não seja mencionado diretamente, o porquê do silêncio e da exclusão de Timóteo: a sua homossexualidade. E procura vivê-la, ora sem se importar com o estigma do nome Meneses que carrega, ora percebendo que isso tolhe o estágio integral de sua sexualidade. É por meio do "Diário de Betty" que ficamos sabendo das condições e transformações de Timóteo após o seu autoenclausuramento:

https://periodicos.unifap.br/index.php/letras Macapá, v. 6, n. I, Io semestre, 2016. 


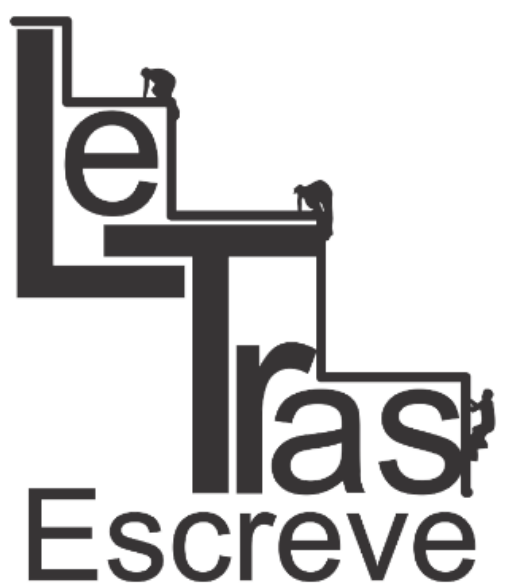

(ISSN 2238-8060)
Ainda daquela vez pude constatar a bizarrice dos costumes que constituíam as leis mais ou menos constantes do seu mundo: ao me aproximar, verifiquei que o Sr. Timóteo, gordo e suado, trajava um vestido de franjas e lantejoulas que pertencera à sua mãe. O corpete descia-Ihe excessivamente justo na cintura, e aqui e ali rebentava através da costura um pouco de carne aprisionada, esgarçando a fazenda [tecido] e tornando o prazer de vestir-se daquele modo uma autêntica espécie de suplício. Movia-se ele com lentidão, meneando todas as suas franjas e abanando-se vigorosamente com um desses leques de madeira de sândalo, o que o envolvia numa enjoativa onda de perfume. Não sei direito o que colocara sobre a cabeça, assemelhava-se mais a um turbante ou a um chapéu sem abas, de onde saíam vigorosas mechas de cabelos alourados. Como era costume seu também, trazia o rosto pintado - e para isto, bem como para suas vestimentas, apoderara-se de todo o guarda-roupa deixado por sua mãe, também em sua época famosa pela extravagância com que se vestia (CARDOSO, 2009, p. 53).

O autoenclausuramento de Timóteo em um dos quartos da casa, local proibido e ignorado pelos demais moradores, desenvolve, parcialmente, alento neste personagem. Recolhido em seu canto, Timóteo centra-se em seus próprios pensamentos e desejos. Sobre ele, Rafael Sousa (2011) escreveu "Timóteo, embora tomado como louco, talvez seja a personagem com maior lucidez ante o espetáculo" (SOUSA, 2011, p. 109). É importante perceber que Timóteo apresenta uma visão mais organizada sobre o perfil dos Meneses, embora todos estejam mergulhados em conflitos pessoais.

Por meio do uso de vestimentas antigas, que pertenceram a sua mãe, que no dizer de Bachelard (1978) são "objetoslembranças", ele revive a memória desta mulher que fora famosa por sua forma provocadora com que se vestia. O canto no mundo de Timóteo, que se transforma em um armário de recordações, uma vez que as lembranças de rejeição por parte de seus irmãos não foram apagadas, mas colocadas em ordem e para, além disso, a sua solidão é projetada em um miraculoso desejo de vingança. Amanda Faria (2011) acentua o seguinte: 


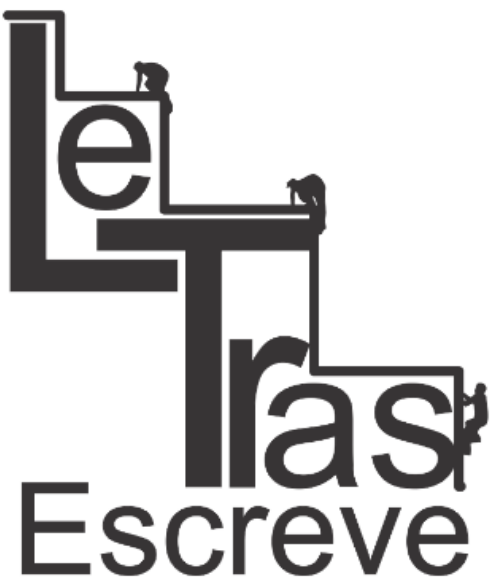

(ISSN 2238-8060)
[...] acompanhando a degradação da casa, mesmo que só a vivenciasse em sua virtualidade, Timóteo se torna cada vez mais grotesco, segundo os relatos dos outros narradores. Talvez, dentre todos os personagens da narrativa, ele seja o que mais sofre com a passagem do tempo e sua a [sic] deterioração extrapola os limites do visível, chegando a consumir até mesmo a sua personalidade, deixando-lhe como única razão de viver a possibilidade de um dia ver, aqueles que roubaram a sua vida, destruídos (FARIA, 2011, p. 80, grifo nosso).

Uma vez que a indumentária feminina que cobre o corpo de Timóteo serve para fragilizar a honra da família Meneses ou até mesmo destruí-la de uma vez por todas, caso venha se expor publicamente. Fato que acaba ocorrendo no final do romance.

O espaço reduzido onde Timóteo escolhe se esconder, "o canto 'vivido' recusa a vida, restringe a vida, esconde a vida. $\mathrm{O}$ canto é, então, uma negação do Universo" (BACHELARD, 1978, p. 286). Assim, o personagem em questão passa a ter uma vida reclusa e protesta pelo silêncio o tratamento de agressividade e rejeição familiar, nutrindo um desejo de vingança.

É importante retornar a discussão entre Timóteo e Demétrio e evidenciar a grande ambição da família Meneses, principalmente de Demétrio, uma visita do Barão. A família do Barão, em Vila Velha, era a única que estava acima dos Meneses, tanto em tradição quanto em fortuna e a visita do Barão mostraria a todos os moradores a importância e bons relacionamentos dos Meneses. No entanto, Timóteo considerava esta situação como uma excelente oportunidade para extinguir, definitivamente, a família Meneses. Amanda Faria (2011) adverte:

[...] o dinheiro da família se esvaía e a casa se encontrava em estado de decrepitude, de modo que apenas mostrando à sociedade que ainda possuíam bons relacionamentos, os Meneses seriam capazes de conservar o seu status de família poderosa da região. Por meio de seus relacionamentos, manteriam um lugar que consideravam justo na sociedade. Dessa maneira, a dita visita vai se tornando a obsessão de todos os habitantes da Chácara: no caso de Demétrio, pelo que foi descrito, no caso de Timóteo, por enxergar aí a

https://periodicos.unifap.br/index.php/letras

Macapá, v. 6, n. I, Io semestre, 2016. 
possibilidade de destruir, de uma vez por todas, os Meneses (FARIA, 2011, p. 81).

Timóteo aguardou a visita do Barão por ocasião do velório de Nina para fazer a sua aparição em público, após um amplo período de tempo enclausurado em seu quarto, longe dos olhos da família e da sociedade. "Timóteo pretende com isso escandalizar a todos com sua presença, posto que ele representa o lado obscuro dos Meneses, por isso fora aprisionado em seu quarto" (SOUSA, 2011, p. 60). Com o intuito de evidenciar esta situação, ressaltamos o seguinte fragmento do romance:

[...] de repente, sem qualquer espécie de aviso prévio, com a brutalidade das grandes surpresas, aquele espetáculo estatelou-se aos nossos olhos: Timóteo, numa rede, conduzido por três pretos, provavelmente os mesmos que tinham vindo comunicar a chegada do Barão (CARDOSO, 2009, p. 473).

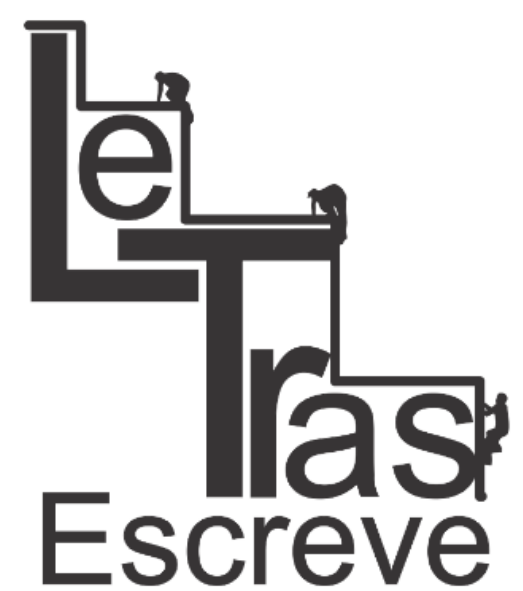

(ISSN 2238-8060)

Lento, ele [Timóteo] percorreu com o olhar a multidão fascinada que o fitava: ninguém ousava fazer um só gesto, nem pronunciara a mínima palavra [...] ah, porque eu [Valdo] também sentia que era Demétrio o fundamentalmente atingido com aquele gesto, e era ele quem pagaria mais caro, com o preço total da sua demissão e da sua vergonha (CARDOSO, 2009, p. 475).

Deste modo, no final da narrativa, Timóteo rompe com os limites espaciais do seu canto no mundo e nutrido por um desejo de concretização de seu plano de desmoralizar a sua família mineira, burguesa e tradicional perante a sociedade adentra outros espaços da casa, depois de um longo período trancafiado em seu quarto.

De acordo com Bachelard (1978), "então, do fundo de seu canto, o sonhador se recorda de todos os objetos de solidão, dos 


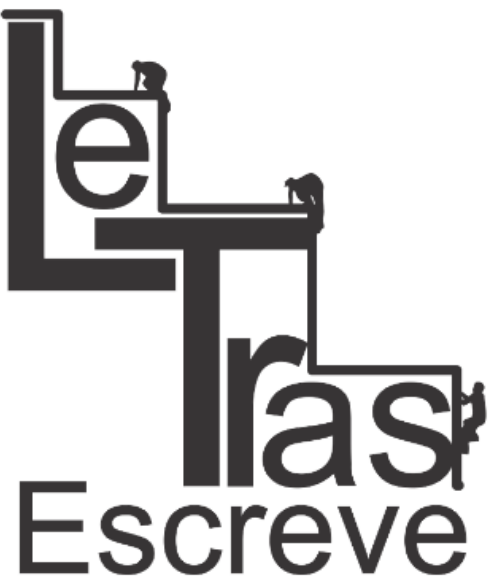

(ISSN 2238-8060)

objetos que são as lembranças de solidão e que são traídos unicamente pelo esquecimento, abandonados num canto" (BACHELARD, 1978, p. 290). Depreende-se que o canto no mudo guarda uma teia de lembranças e que é acionada pelo indivíduo em sua relação de identificação e elaboração do espaço.

Diante do procedimento comportamental e da relação de Timóteo com os "cantos da casa", vemos que a casa dos Meneses de maneira paradoxal "não conforta, nem protege", como afirma Bachelard (1978). Ela aprisiona e devora seus moradores, seres quase reificados no ambiente do qual não conseguem se desprender.

Se a "casa é nosso canto do mundo. Ela é, como se diz frequentemente, nosso primeiro universo. É um verdadeiro cosmos. Um cosmos em toda a acepção do termo. Até a mais modesta habitação, vista intimamente, é bela" (BACHELARD, 1978, p. 200). Em Lúcio Cardoso, ela representa um aprisionamento psicológico e mesmo físico no caso de Timóteo, como também de uma ampla inconformidade que aponta para a degradação moral e econômica dos Meneses.

O casarão da chácara é um tipo de construção que ao invés de "proteger e confortar", como defende Bachelard (1978), torna-se um cárcere. O que não é sem motivo, posto que os personagens tratam interno e silenciosamente os seus piores dramas ao presenciarem cotidianamente a decadência econômica e moral da família Meneses e de si.

Finalizando por enquanto...

Nesse sentido, mostrou-se extremamente relevante o estudo da simbologia do espaço e a relação com as ações dos personagens, de modo mais particular de Timóteo. Tal relação que se mostrou conflituosa é de fundamental importância na constituição do romance Crônica da casa assassinada, de Lúcio Cardoso. Assim, 
em meio à desestruturação familiar, Timóteo, em seu autoenclausuramento, é marcado pela negação ou rejeição de seus irmãos, em particular de Demétrio, em seu "canto do mundo" é imerso em suas reflexões e, por meio da posse das roupas e pertences antigos que eram de sua mãe, arquiteta uma forma de afrontar e fazer ruir de vez a sua patriarcal, burguesa e complexa família.

Focalizamos, ainda, Bachelard (1978) que defende a tese da imagem de uma casa como um espaço que proporciona uma atmosfera de proteção, refúgio e acolhimento aos seus habitantes. No entanto, no romance cardosiano, alvo de nossas reflexões, a casa dos Meneses não provoca um clima de abrigo, pelo contrário, é um espaço segregacionista e excludente aos moradores, contrapondo a casa pensada por Bachelard (1978), como podemos constatar ao longo deste trabalho. Assim, o estudo feito sobre a história de Timóteo e o seu autoenclausuramento, atenta para este ponto fulcral do romance na medida em que percebemos 0 isolamento do personagem em um quarto, que se assemelha mais a uma prisão.

\section{Referências bibliográficas}

ANDRADE, Luiz Eduardo da Silva. Uma família de objetos: o espaço em crônica da casa assassinada. Anais do III Encontro de PósGraduação em Letras da UFS. São Cristóvão, v. 3, p. 1274-1284, 2010.

BACHELARD, Gaston. A filosofia do não; O novo espírito científico; A poética do espaço. Trad. Joaquim Ramos et al. São Paulo: Abril Cultural, 1978. p. 181-349.

CARDOSO, Lúcio. Crônica da casa assassinada. Rio de Janeiro: Civilização Brasileira, 2009. 517 p. 
CORREAA, Ana Laura dos Reis. Lúcio Cardoso e a crônica da ruína e da desagregação em região periférica. Interdisciplinar, Sergipe, v. 3, n. 5, p. 81-100, jan.-jun. 2008.

DIMAS, Antonio. Espaço e romance. São Paulo: Ática, 1994.

FARIA, Amanda Miranda. O espaço em Crônica da casa assassinada, de Lúcio Cardoso. Crátilo, Patos de Minas, n. 4, p. 7684, 2011.

HALL, Stuart. A linguagem silenciosa. Lisboa: Relógio D’Água, 1994. SOUSA, Rafael Batista de. Um concerto de vozes dissonantes: o moderno e o arcaico em A crônica da casa assassinada de Lúcio Cardoso. Brasília, 2011. 123 p. Dissertação de Mestrado em Letras, Universidade de Brasília.

Recebido em 13/07/2016. Aprovado em 20/08/2016.

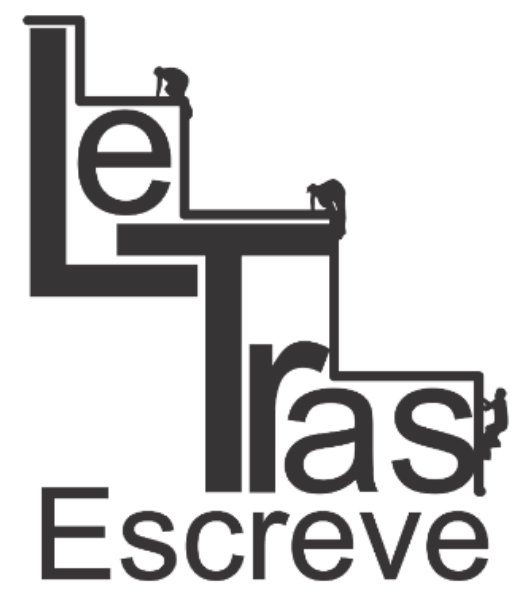

(ISSN 2238-8060) 